\title{
Dialéctica negativa y sufrimiento en la filosofía moral de Theodor W. Adorno*
}

Fecha de entrega: 16 de octubre de 2019

Fecha de evaluación: 27 de enero de 2020

Fecha de aprobación: 3 de marzo de 2020

Tulia Almanza Loaiza**

\section{Resumen}

El objetivo de este artículo es mostrar que en la actualidad el dominio de la técnica sobre la naturaleza tiene consecuencias en la conformación de la subjetividad. Para comprender este dominio, la dialéctica negativa analiza las tensiones entre el mito y la razón, para señalar las oposiciones del sujeto en su relación con la sociedad. La dominación causa sufrimiento en el sujeto, lo que se refleja en su interacción con los objetos y en la conformación de su moralidad.

Palabras clave: dialéctica negativa, diferencia, subjetividad, sufrimiento, filosofía moral.

* Este artículo es resultado de la investigación "Sufrimiento y victimas en la filosofía moral de Theodor W. Adorno", realizado con el apoyo de la convocatoria interna 2018 de la Universidad de San Buenaventura, Bogotá. Citar como: Almanza Loaiza, T. (2020). Dialéctica negativa y sufrimiento en la filosofia moral de Theodor W. Adorno. Cuadernos de Filosofía Latinoamericana, 41(123), 51-76. Dol: https://doi.org/10.15332/25005375/5990

* Profesora de la Universidad de San Buenaventura, Antropóloga de la Universidad de los Andes, Magíster en Filosofia de la Universidad Nacional de Colombia, Especialista en Docencia Universitaria y Doctora en Humanidades, Humanismo y Persona de la Universidad de San Buenaventura. Sus investigaciones se centran en la teorización acerca del sufrimiento de las víctimas. Correo electrónico: TAlmanza@usbbog.edu.co 


\section{Negative Dialectics and Suffering in Theodor W. Adorno's Moral Philosophy}

\section{Abstract}

The aim of this article is to show that the ascendancy of technique over nature has implications in the conformation of subjectivity. In order to understand such ascendancy, negative dialectics brings forth the tensions between myth and reason, which reveal the subject's contradictions in its relation with society. Domination causes suffering in the subject, which is reflected in its relation with objects and in the shaping of its morality.

Keywords: Negative Dialectics, Difference, Subjectivity, Suffering, Moral Philosophy.

\section{Introducción}

Abordar la historia desde la dialéctica negativa implica desmitificar los conceptos, revelar lo oculto, lo prehistórico, para develar el mito que yace subordinado a la razón. En este contexto, el mito y la razón actúan como polos opuestos que comprenden al sujeto en sus distintas facetas, no como la antítesis entre el individuo y la sociedad, sino como la manifestación de la desintegración y la irracionalidad en la relación entre el individuo y la sociedad — en el marco de su aparente racionalidad-. En este artículo pretendo analizar cómo la constitución del sujeto se mueve en medio de tensiones entre las creencias y la racionalidad objetiva, que generan sufrimiento en el sujeto, el cual se refleja en la relación del sujeto con los objetos y en la conformación de su moralidad. Desde la dialéctica negativa de Theodor W. Adorno, la constitución de la subjetividad bajo la dominación social cobra un costo muy alto al sujeto, que consiste en la restricción del pensamiento y de la reflexión crítica de las situaciones conflictivas, que coarta su libertad e impide la acción y las decisiones autónomas. 


\section{Dialéctica e historia natural}

\section{Dominio de la naturaleza, dominio del hombre}

En la relación entre hombre y naturaleza el mito ha quedado siempre subordinado a la razón y, sin embargo, el mito vuelve a aparecer en medio de la racionalidad. En este análisis desarrollado en el ensayo "El concepto de Ilustración”, Horkheimer y Adorno (2009) pretendían desmitificar los conceptos y los fenómenos históricos ubicándolos en polos opuestos que mostraran momentos dinámicos. Lo natural aparece como "segunda naturaleza", es decir, históricamente producido y enajenado, y lo "histórico" como primera naturaleza, es decir, como lo material. También aparece otra manera de desmitificar los conceptos, al volver a presentar los momentos arcaicos que hacen parte del presente, como elementos claves de la actualidad. Algunos autores asumieron esta manera de proceder para identificar lo arcaico en la Modernidad, como una estrategia para abrir el mundo petrificado a la comprensión crítica, como una dialéctica sin identidad, según señala Susan Buck-Morss (1981, p. 130).

En el método dialéctico, el mito y la razón son polos opuestos que hacen aparecer al sujeto en sus distintas facetas. En la antítesis entre individuo y sociedad, el hombre se enfrenta a la naturaleza como una forma de dominación, como un poder mítico al cual superar, pero al mismo tiempo, en vez de superar a la naturaleza, el individuo cae bajo la dominación de la segunda naturaleza (Horkheimer y Adorno, 2009, p. 68). Adorno explica el "concepto de historia natural" a partir de los trabajos de Georg Lukács y de Walter Benjamin. Del primero tomó el concepto de "segunda naturaleza", que se refiere a su idea histórica y filosófica de un mundo lleno de sentido y otro vacío de sentido. Este mundo vacío de sentido es el inmediato, enajenado, lleno de mercancías, que Lukács intentó describir (Lukács, citado por Adorno, 2010, pp. 324-325).

No se trata solo de las oposiciones que genera la historia natural, en cuanto conocimiento y producción material. También el momento arcaico superpone el conocimiento natural a la identidad del hombre, y orienta en el mismo plano el proceso de conocimiento y del ritual mágico, que transfiere a cada uno sus características. Al ser procedimientos similares y al mismo tiempo opuestos, tanto en el ritual como en el proceso de conocimiento, el sujeto que conoce posee ahora una máscara, con la que sigue los rituales que ha realizado el chamán en su culto. En la Antigüedad los ritos se dirigían a los elementos naturales con una máscara que variaba de acuerdo con 
los diversos espíritus malignos o benignos. El mundo mágico premoderno mantenía diferencias en la narración de los mitos, en la ejecución de los rituales, en la interpretación de las tradiciones. Así, la magia perseguía sus fines por medio de la mímesis ${ }^{1}$, es decir, en la imitación de los flujos naturales y sus ciclos, para transformar los objetos naturales en imágenes y símbolos; a diferencia de la ciencia, que orienta sus fines por medio de una distancia creciente entre sujeto y objeto.

Aquí encontramos el manejo de las contradicciones de manera superpuesta. Por un lado, la mímesis propia de la magia y los rituales míticos no desaparece con el advenimiento de la razón ilustrada. Esta última permanece en el arte que se diferencia de la ciencia donde se produjo un distanciamiento entre sujeto y objeto. La ciencia ha sustituido los procedimientos rituales al independizar el pensamiento del objeto, así como le ocurre al sujeto frente a la realidad. Sin embargo, para que las prácticas del chamán y su eficacia sobre el mundo pudieran ser sustituidas por la técnica industrial, era necesario que el pensamiento se independizara de los objetos, como efectivamente se ha venido dando en la adaptación del sujeto a la realidad (Horkheimer y Adorno, 2009, p. 68). Pero la dialéctica histórica de la razón que consistía en la negación del mito completa su ciclo al retornar otra vez al mito en tiempos actuales, es decir, la separación entre sujeto y objeto que retorna a la mímesis como procedimiento, y el sujeto con su imprescindible máscara para el ritual. Esta dialéctica aparece moviendo la historia y por tanto esa distancia entre pensamiento y objeto queda atrapada en la mitología que se entremezcla con la marcha del progreso; el camino de la teoría y de los avances de la ciencia caen bajo la crítica de ser una mera creencia, verdad provisional, necesidad de reemplazar a cada paso una técnica con otra nueva. Por tanto, el pago que el mito exige por cada suceso también se extiende a la historia cuando cada hecho paga con su propia aniquilación; actualmente, el pensamiento no se sorprende ante nada nuevo, los experimentos pueden anticipar los resultados, las grandes teorías ya fueron pensadas.

Los sujetos, entretanto, solo tienen que adaptarse a las condiciones de sobrevivencia, de manera que aquello que podía ser distinto es igualado, pues las diferencias que caracterizan a los sujetos entre sí se vuelven idénticas en la producción económica,

1 Efectivamente, Buck-Morss aclara: "la mimesis tiene su origen en la magia primitiva, en la imitación de la naturaleza por el chamán. Al desintegrarse la magia, la mímesis sobrevivió como un principio de representación artística" (1981, p.188). El carácter transformador del momento mimético debe ser tomado de manera literal, como cuando los objetos musicales mutan en palabras o en imágenes. 
que ha estandarizado sus procesos. Las formas de conocimiento se producen en medio de la historia natural, por tanto, la primera naturaleza exige de los hombres pasar a la "segunda naturaleza", que como ya he señalado, siguiendo a Adorno, es una naturaleza enajenada. Dentro de esta enajenación los sujetos no están en condiciones de inventar un mundo distinto para ser ellos mismos, sino que son individuos únicamente para sobrevivir. La sobrevivencia es igual para todos, pero no para superar la dominación y la enajenación, sino para seguir viviendo, para la producción de mercancía o de conocimiento. Pareciera que la Ilustración pudiera superar las antiguas desigualdades que produjeron la dominación ejercida por reyes y sacerdotes sobre el pueblo; pero si su manera de conocer el mundo se unifica en una sola vía, entonces cada elemento tiene que ver con otro, cada concepto se iguala con su opuesto y las formas distintas de pensar quedan anuladas.

En esta situación de homogenización la dialéctica puede contrarrestar esta lógica, una dialéctica que significa pensar en contradicciones experimentadas en la cosa y en contra de ella. "Siendo contradicción en la realidad, es también contradicción a la realidad. Pero dicha dialéctica no es conciliable con Hegel. Su movimiento no tiende a la identidad con la diferencia de cada objeto con su concepto, más bien desconfía de lo idéntico" (Adorno, 1975, p. 148). Se trata de la propuesta de dialéctica negativa, que pretende desmoronar las figuras armadas y objetualizadas que el sujeto tiene frente a sí, en cuanto que esas figuras son en realidad falsas. Años después de Dialéctica de la Ilustración (2009), Adorno propuso la dialéctica negativa como la manera de salir de la dominación que la razón ilustrada le imponía al sujeto, es decir, de la pura identidad entre concepto y cosa. El sujeto tendría que adoptar una postura crítica que le permitiera darse cuenta de lo diferente para separarse del pensamiento identificante. Pero ya entonces Adorno sabía que esta postura crítica es difícil de asumir cuando el sujeto está sometido a las relaciones concretas del trabajo, valorado como tiempo de trabajo necesario para la producción de la mercancía. "Y es que el canje de equivalentes es desde tiempo inmemorial un nombre para intercambiar lo distinto apropiándose la plusvalía del trabajo" (Adorno, 1975, p. 150). Por tanto, el hombre está sujeto a las condiciones de trabajo y de sobrevivencia a las que la primera y la segunda naturaleza lo obligan, una dominación igual para todos, que elimina las particularidades de cada hombre. La historia natural atraviesa la constitución de la sociedad ilustrada, una historia que debe ser leída "a contrapelo" 2 para sacar sus contradicciones y una

2 Expresión usada por Walter Benjamin en "Tesis sobre la historia" para expresar que la historia ha sido leída por los vencedores, quienes en su conquista dejaban a su paso ruinas y vencidos. Una lectura 
naturaleza doble, primera y segunda, ambas sometidas y enajenadas por el dominio de la razón. El sujeto de conocimiento que domina la naturaleza trabaja para sobrevivir en la "segunda naturaleza", se identifica con los demás sujetos y hace homogénea su propia individualidad.

La igualdad producto de la homogenización se consagra en el mercado, que no considera al sujeto por sus cualidades particulares, pues lo importante es el intercambio de su mercancía por otra. El sí mismo de los hombres, que ha sido dado como propio y por tanto distinto de los demás, se convierte en igual en el mercado, pero esa igualdad la alcanza por medio de la coacción. Los colectivos que la sociedad de mercado desarrolla consisten en la negación de cada individuo singular, que para alcanzar esa anulación requiere de una igualación represiva. Horkheimer y Adorno afirman que la Ilustración aceptó la coacción social incluso en los sistemas democráticos, pues facilitaba la producción de mercancías; la asimilación de los individuos al colectivo permitió luego el manejo de la ideología en los regímenes totalitarios:

\begin{abstract}
La horda, cuyo nombre aparece sin duda en la organización de las juventudes hitlerianas, no es una recaída en la antigua barbarie, sino el triunfo de la igualdad represiva, la evolución de la igualdad ante el derecho hasta la negación del derecho mediante la igualdad. El mito de cartón piedra de los fascistas se revela como el mito auténtico de la prehistoria, pues mientras este desveló la venganza, aquel, el falso, la ejecuta ciegamente sobre sus víctimas. (Horkheimer y Adorno, 2009, p. 68)
\end{abstract}

La identidad y la homogenización son formas utilizadas por la ideología, en el sentido de adecuar la realidad a formas violentas de imposición, ideología que igual sirve para organizar a los jóvenes en una masa obediente, como para falsear los derechos democráticos de la igualdad para ejecutar actos de barbarie y, así, la Ilustración produce víctimas. Por tanto, cuando Horkheimer y Adorno evidencian que la igualdad y la identidad no son conceptos modernos o ilustrados que superen la medievalidad oscura o la Antigüedad perdida, sino, por el contrario, arguyen que estos conceptos modernos se convierten en partes de un mito que sirve a los regímenes fascistas o totalitarios para producir crueldad sobre los hombres.

crítica de la historia "considera cometido suyo pasarle a la historia el cepillo a contrapelo" (Benjamin, citado en Adorno, 2010b, p. 63). 
Buck-Morss analiza que en estos momentos del texto Horkheimer y Adorno pretendían desafiar las teorías burguesas desde adentro. La crítica a la historia y al progreso provenía de su propuesta de historia natural, que anteponía al pensamiento liberal la realidad contradictoria, de la justicia, la razón y el individualismo, la realidad de la sociedad burguesa mostraba la injusticia, la irracionalidad y un capitalismo que reducía a los individuos a sobrevivir (Buck-Morss, 1981, p. 145). Horkheimer había involucrado su postura moral ante la injusticia, cuando claramente mostraba que estas contradicciones implicarían un sufrimiento de los individuos que tenían que someterse a la competencia en el sistema de producción capitalista, aspecto que luego Adorno también adoptó (Buck-Morss, 1981, pp. 148-149).

Así mismo, el nuevo significado de lo arcaico revelaba que el camino del progreso repite los esquemas, las formas de poder, que el mito había usado. El relato y el ritual ponían límites a lo conocido y amenazaban a quien se aventurara ir afuera. El mito identificaba la vida con la muerte, así como también la Ilustración identifica lo viviente con lo no viviente, al asimilar esta identidad mediante la lógica y los conceptos establecidos a la universalidad del objeto, y establecer límites al conocimiento: "Nada absolutamente debe existir fuera, pues la sola idea del exterior es la genuina fuente del miedo" (Horkheimer y Adorno, 2009, p. 70). Si el mundo guiado por los mitos es cerrado, entonces nada puede escapar a su destino; y si el mundo mítico y el ilustrado no han logrado separarse, sino que guardan una relación dialéctica, la justicia mítica y la ilustrada se relacionan en una ecuación de equivalencia. Por tanto, el sujeto que espera seguridad y justicia en una sociedad moderna de mercado, productora de mercancías y de conocimientos y técnicas nuevas, identifica esta producción con la justicia. Espera que la justicia sea igual para todos, pero en realidad la justicia termina siendo dominación y ajuste con el destino.

\section{Dominación y formación de la subjetividad}

Buck-Morss (1981) afirma que Dialéctica de la Ilustración recibió una gran influencia de las Tesis sobre la filosofía de la historia, texto enigmático calificado por la autora como uno de los más importantes y significativos de Benjamin, junto a El libro de los pasajes y el Origen del drama barroco alemán. En 1929, Adorno y Benjamin se habían comprometido en una declaración sobre la verdad histórica: "la verdad de cualquier fenómeno pasado no era estática, exterior a la historia, sino inmanente y por lo tanto mediatizada por un presente continuamente cambiante" (Benjamin, citado por 
Buck-Morss, 1981, p. 133). Esta visión interpretaba la articulación de los orígenes históricos no como un descubrimiento del pasado, sino que intentaba reconstruir el prototipo histórico o el desarrollo histórico desde la perspectiva del presente, con el propósito de contar con una fuente para criticar ese presente. La dialéctica de la Ilustración pretendía precisamente reconstruir los orígenes de la Ilustración en sus diversas temáticas, como la razón, la libertad, la ciencia y la subjetividad. En este sentido, la autora afirma:

Y cuando el primer "Excursus" interpretaba a Odiseo como el prototipo (Urbild)
del individuo burgués, el propósito no era desafiar al paradigma marxista de
la historia como lucha de clases, sino el leer esta imagen arcaica como una
configuración de la Modernidad, de modo que [pudiera] transformarse en la
ocasión para una comprensión crítica del presente. (Buck-Morss, 1981, p. 133)

El análisis de este excurso se centra en la crítica del individuo burgués, que ofrece una perspectiva interesante acerca del agotamiento del sujeto moderno y, por tanto, permite comprender mejor la crisis de la Modernidad en los pilares que la sostienen. Es importante aclarar que estos ensayos de la Dialéctica de la Ilustración fueron escritos cuando el orden burgués se encontraba en ruinas, precisamente cuando todos sus valores y mayores símbolos como la democracia, el mercado, la libertad y la razón se habían entronizado de tal manera que parecían una "segunda naturaleza", es decir, una apariencia de progreso. Tal era el desconcierto que estos intelectuales sentían frente al desasosiego de ver que las fuerzas revolucionarias habían terminado en el totalitarismo nazi y la Revolución rusa en el régimen estalinista.

Por ello, Benjamin consideró que el mayor obstáculo para la conciencia revolucionaria había sido la aceptación estática de la historia como progreso, es decir, de la historia como una "segunda naturaleza". Para romper con esta corriente, Horkheimer y Adorno asumieron este análisis crítico e iconoclasta que pretendió romper con dos grandes íconos: la razón ilustrada y los héroes griegos, pues estas épocas del pasado intocadas y perfectas se solapaban con los fenómenos bárbaros del presente (BuckMorss, 1981, p. 135).

El análisis del poema homérico cobra una gran importancia, por cuanto constituye un símbolo de la Antigüedad, un prototipo de la antigua ilustración que permite ser traído al presente. Si se aprehende esta figura como un elemento arcaico que funge como 
alegoría en la historia natural, como una manera de interpretar la historia presente y concreta, entonces podemos relacionar el análisis de esta obra emblemática con la crítica dialéctica a la Ilustración. Adorno y Horkheimer se interesaron por descubrir las escenas, las relaciones simbólicas y alegóricas dentro del poema arcaico, con el propósito de pasar de la literatura a la historia. Por ello, vuelvo al ensayo de Adorno acerca de "La idea de historia natural", donde el autor había afirmado que "la alegoría es expresión”, siguiendo a Benjamin (citado por Adorno, 2010, p. 327). Que la alegoría sea expresión significa que ella misma crea las condiciones históricas, relaciones históricas entre lo que aparece la naturaleza y aquello significado, es decir, lo transitorio, por ello la alegoría como expresión es historia sin más. Adorno, además, también cita a Benjamin en ese famoso ensayo donde habla de la relación entre símbolo y alegoría; allí el símbolo transfigura la caída, es el rostro transfigurado de la naturaleza que puede recuperarse en la redención; en cambio, la alegoría se ofrece como paisaje paralizado. La alegoría no es libre en su expresión, carece de las formas clásicas de lo humano, pero expresa "la naturaleza de la existencia humana sin más" y además expresa la biografía del individuo bajo

[...] una figura de naturaleza caída llena de significado. Este es el núcleo de toda mirada alegórica, de la exposición barroca, mundana, de la historia como historia del sufrimiento del mundo; historia que solo es significativa en las estaciones de su ruina. (Benjamín, 2010, p. 383)

En su ensayo de la "La idea de historia natural", Adorno (2010, p. 327) recuerda esta referencia a la alegoría, es decir, casi dos décadas antes del estudio sobre Odiseo, y sin embargo, se actualiza en este análisis por cuanto la visión de la historia de Benjamin que se aparta de los datos y los hechos político-económicos, abre en cambio las puertas hacia otras dimensiones: el hombre en su caída sobre las ruinas que él mismo ha producido. Tanto la caída como la ruina significan e implican un sufrimiento del hombre que cae y que puede incluso morir. La segunda naturaleza aparece también en este escenario, donde las obras de los hombres, su cultura y los productos de su trabajo están enajenados y, por tanto, no ven la luz sino la ruina.

Por tanto, esta interpretación benjaminiana de la historia se diferencia de la historia del progreso, y en el caso del análisis de La Odisea se lanza a dotar de significado a la protohistoria, a la prehistoria de los antiguos símbolos que aparecieron de nuevo en 
las sociedades más avanzadas. En su análisis, Odiseo es el símbolo del sujeto triunfante, que tiene que sacrificarse a sí mismo para alcanzar el éxito.

\section{Sufrimiento y pathos afectivo}

\section{Sufrimiento e identidad}

El proceso de conformación del sujeto tiene una historia, que se mueve desde los mitos arcaicos hasta las teorías ilustradas, siendo ese movimiento una alternancia de tensiones entre las creencias y la racionalidad objetiva. Sin embargo, la historia pretende ser lineal y superar los estadios anteriores con el propósito de que los mitos no hagan parte de nuestra condición actual, aunque los mitos mismos se han trocado en postulados de la ciencia moderna.

Esta historia se remonta hasta la prehistoria misma, hasta el mito, cuando el hombre antiguo tuvo que enfrentar caminos difíciles que impidieron que la naturaleza de donde proviene, y a la que pertenece la especie humana, pudiera seguir ligada a ella; sin embargo, el hombre civilizado pretende superar la naturaleza - como si no tuviera que trabajar y proveerse de los recursos para sobrevivir-, es decir, construir una brecha entre la naturaleza y el hombre como especie. Pese a esa pretensión, los individuos ilustrados quedaron atrapados en su propia historia mitológica, aunque quisieran salir de ella ejerciendo la venganza, pues tal como ocurre en los mitos "todo cuanto sucede debe pagar por haber sucedido” (Horkheimer y Adorno, 2009, p. 67). Así mismo ocurre en la sociedad ilustrada, cada acontecimiento es aniquilado apenas ha sucedido, lo cual nos hace pensar que cada vez que sobreviene un hecho nuevo olvidamos el anterior. Por ejemplo, los sujetos modernos creyeron que se habían liberado de las repeticiones rituales al pasar a otras formas de relaciones distintas, donde no tenían que identificarse con la figura mítica o con el ritual repetitivo. El hombre moderno creyó que la libertad era su nueva condición legal que obedecía la ley natural, según la cual ceder su propio poder en un contrato garantizaría su supervivencia. Por tanto, el sujeto no ha escapado al mito ni a la autoconservación ${ }^{3}$, pues no es verdad que en la Modernidad la historia haya superado los niveles inferiores y ahora los hombres puedan gozar de una mayor autonomía y diferenciación de los demás. Por el contrario:

3 En el apartado anterior he tratado el concepto de autoconservación siguiendo la orientación adornianomarxista que enfatiza en las relaciones materiales de los hombres con la naturaleza, cuyo objetivo es la supervivencia, y que Adorno mantiene en su estructura teórica. 
Lo que podía ser distinto, es igualado. Tal es el veredicto que erige críticamente los límites de toda experiencia posible. La identidad de todo con todo se paga al precio de que nada puede ser idéntico consigo mismo. La Ilustración deshace la injusticia de la vieja desigualdad, la dominación directa, pero la eterniza al mismo tiempo en la mediación universal, en relación de todo lo que existe con todo. (Horkheimer y Adorno, 2009, p. 67)

Es decir, la historia moderna ha prometido el surgimiento de la identidad del sujeto, como la delimitación de un sujeto individual distinto de los demás, diferenciados de ellos con sus características propias de personalidad, autonomía, libertad, capacidades, etc. Sin embargo, la identidad del sujeto sufre una doble dominación: por una parte, se ve obligada a homogenizar su carácter al limitar su experiencia a las relaciones ya establecidas en la sociedad, por ello en la Modernidad las relaciones de competencia en el mercado obligan al sujeto a mejorar constantemente su productividad, a consumir las mercancías que le ofrece e impone la moda, a pensar y decidir dentro de los modelos establecidos por las clases superiores, especialmente por la clase burguesa, es decir, por las ideologías liberales tendientes a la racionalidad instrumental, la secularización y la formalización de la política y de la ética.

Por otra parte, en el ámbito privado, las relaciones también son establecidas por normas religiosas o costumbres cada vez más permeadas por la cultura ofertada por la industria cultural, lo cual implica que los sujetos individuales no pueden desarrollar particularidades que conformen su identidad individual, sino que se ven forzados a identificarse con los patrones que la cultura les impone. Las relaciones familiares aparentan condiciones de bienestar, compitiendo con sus pares en el consumo, con el propósito de seguir los cánones sociales. Por consiguiente, la desigualdad que antaño existía entre los estratos nobles y las capas inferiores, que implicaba un dominio directo entre un estrato superior y otro inferior se iguala actualmente a través de las relaciones económicas, en donde los sujetos se emplean de manera similar en formas de producción. Estas últimas son ahora el patrón universal que media en cada una de nuestras relaciones sociales y con el mundo, es decir, el patrón universal que elimina las singularidades del pensamiento personal, al obligar a tener conformidad con lo real; así mismo, iguala a todos al no preguntar a ninguno por su origen, pero en cambio el sujeto se deja moldear por el patrón social ajustado al mercado, la identidad con el todo. El sí mismo que haría parte del sujeto, finalmente lo pierde en la sociedad de mercado, allí donde tiene que igualar sus condiciones con los demás para competir 
con ellos por la supervivencia ${ }^{4}$. Es en la época ilustrada cuando parece que la mitología se disuelve y los hechos brutos, que provienen de la injusticia, se consideran inmutables, estos muestran que el dominio recae sobre los hombres en general como sobre cada individuo.

El dominio no se paga solo con la alienación de los hombres con respecto de los objetos dominados: con la cosificación del espíritu fueron hechizadas las mismas relaciones entre los hombres, incluso consigo mismo. Este se reduce a un nudo de reacciones y comportamientos convencionales que objetivamente se esperan de él. (Horkheimer y Adorno, 2009, p. 81)

Adorno y Horkheimer entienden la constitución del sujeto moderno en el sentido de que este no ha seguido un camino de ascenso desde la naturaleza hacia la cultura y la civilización para construir su propia identidad, sino más bien, que en esa pretensión civilizatoria la represión más grande que debe sufrir el sujeto consiste en tener que someterse a sí mismo, por medio de la negación de sus impulsos corporales y con ella la negación de la realidad, o bien ajustarse a una realidad impuesta, lo cual implica sacrificio y dolor. Maiso afirma al respecto que Adorno se concentró en la crítica a la sociedad y en ella la crítica al sujeto, consciente de que para ello el sujeto solo cuenta con la autorreflexión crítica de la razón, e insiste

[...] en lo no-idéntico y en el recuerdo de la naturaleza reprimida en el sujeto, no responde a la necesidad de poner estos elementos "a salvo" de la dinámica destructiva de la racionalidad instrumental, sino que más bien constituye la base epistemológica desde donde plantea su crítica inmanente. (Maiso, 2010, p. 252)

Por ello, Horkheimer y Adorno asumieron la exégesis del texto homérico, que les permitió a los autores el análisis del mito a través de la alegoría, que sacó a la luz la relación de los sujetos con la naturaleza desencantada ligada a la constitución de la subjetividad. Según Maiso, el concepto de astucia aparece en la génesis de la subjetividad que, siguiendo a Freud, Marx y Hegel, implica una derrota de la vida instintiva, una renuncia a los instintos que los sujetos han tenido que aceptar (Maiso, 2010, p. 244).

4 Jordi Maiso plantea una discusión con respecto a la supervivencia y la sociedad de consumo, pues las llamadas sociedades posindustriales superarian las relaciones directas de dominio de la naturaleza, dado que ya no trabajan directamente en la producción, sino que la adjudican a mano de obra inmigrante. De manera que las clases medias y altas pueden dedicarse al consumo y al ocio (Maiso, 2010, p. 280). 
Los autores nos recuerdan que el sí mismo brota de la negación de todo signo natural, de todos los elementos que contuvieran sangre, carne, lágrimas, tanto es así, que el yo debía depurarse de todo signo corporal hasta quedar sublimado.

\begin{abstract}
Quien confía en la vida directamente, sin relación racional con la autoconservación, recae, según el juicio tanto de la Ilustración como del protestantismo, en la prehistoria. El impulso es en sí mítico como la superstición; servir a un Dios a quien el sí mismo no postula, resulta absurdo como la embriaguez. El progreso ha reservado la misma suerte a ambas cosas: a la adoración y a la inmersión del ser inmediatamente natural. Ha cubierto de maldición al olvido de sí tanto en el pensamiento como en el placer. (Horkheimer y Adorno, 2009, p. 83)
\end{abstract}

Por tanto, la constitución del sí mismo no puede confiar en su origen, porque este le hace pagar una recaída en la más antigua historia. Si ahora estamos en la era del progreso tecno-científico, creer en la superstición o en los mitos es tanto así como rechazar las bondades que estos avances nos han dejado y volver al mundo primitivo. El sí mismo tiene que olvidar su pasado natural corporal o mítico ancestral, pues las tensiones que estos juegan con las religiones modernas y con la ciencia son insostenibles. La referencia al pensamiento y al placer me resultan importantes en este contexto reconstructivo de la subjetividad, pues en el discurso sobre la moral, es precisamente el placer el foco donde los pensadores alemanes fijan su atención, donde el análisis crítico de la moral moderna quiere presentar una ruptura, un nuevo quiebre en la subjetividad.

En este contexto, el surgimiento de la moral moderna va ligada a la historia de la razón, cuando el entrelazamiento con la economía de mercado era inevitable. El conocimiento científico basado en los métodos lógicos cuyos resultados vieron su aplicación en técnicas que mejoraron la transformación de la naturaleza, se enfrentaron al otro lado de la razón sin contar con el mito o la religión para contrarrestar su presencia. Desde entonces, los mitos tienden a desaparecer, y por tanto la irracionalidad y los impulsos no encuentran un lugar ni una explicación en este mundo ordenado positivamente. El pensamiento ilustrado no tiene sino que mentirse a sí mismo acerca de la presencia de sus propias expresiones artísticas, sus sentimientos y sus demás impulsos; esas mentiras son la alienación de su razón planificada por el sistema económico-científico. La razón se vuelve fría ante sus propios sentimientos, impasible ante las expresiones pasionales, así se presenten en el cine, como nuevo canal de expresión de la cultura, 
al considerarlos vulgares expresiones que maquillan el producto cultural para la venta y el consumo (Horkheimer y Adorno, 2009, p. 139). Sin embargo, y pese a todos los esfuerzos por controlar los impulsos somáticos, estos no pueden ser graduados por la razón ilustrada, aunque esta se esforzó por equilibrar el camino de progreso, en el que tuvo que superar las etapas anteriores por la fuerza. El paso del animismo a la magia y luego a las religiones; el surgimiento de los imperios y su expansión dominadora por medio de la fuerza, siguieron el impulso de la autoconservación, así como de la racionalización, para superar los estadios anteriores y sustituir las viejas mitologías por nuevas más ilustradas.

\section{Subjetivación y moral kantiana}

Horkheimer y Adorno recurren a la obra literaria del Marqués de Sade, Historie de Juliette (1797) (citado por Horkheimer y Adorno, 2009, p. 135), pues esta obra representa una crítica demoledora de la razón práctica kantiana. Por medio del análisis literario nos quieren mostrar cómo esta obra eleva el paso del principio científico a principio destructor, en una línea de tiempo que transcurre entre los avances del progreso y la transformación de los viejos tabúes en comportamientos abominables, con el propósito de instaurar un orden nuevo. En contraste con Kant, Sade interpreta la moral a través de dos hermanas, Justine y Juliette.

Justine, la buena de las dos hermanas, es una mártir de la ley moral. Juliette, es verdad, saca la consecuencia que la burguesía quería evitar: ella demoniza al catolicismo como última mitología, y con él demoniza a la civilización en cuanto tal. Las energías que se dirigían al sacramento se orientan ahora, invertidas, al sacrilegio. (Horkheimer y Adorno, 2009, p. 141)

Juliette practica ciertos comportamientos sacrílegos considerados tabú, orientados a la destrucción de las relaciones sociales y de la dignidad de las personas. Eran comportamientos prohibidos en su sociedad, pero ella no los consideraba así, sino que los caracterizaba como prácticas bestiales en las cuales encuentra un placer intelectual, gusto y placer en "destruir la civilización con sus propias armas" (Horkheimer y Adorno, 2009, p. 141). Por tanto, Juliette no se deja convertir en mártir como su hermana, sino que ante todo demoniza al catolicismo y a su moral orientando todas sus energías a las prácticas prohibidas por la religión. Pero lo interesante del comportamiento de Juliette es que no es irracional, sino que, siguiendo a Kant — de manera paradójica—, somete 
todas sus facultades e inclinaciones a su poder, al poder del delincuente. Por ello, "El rostro del asesino debe mostrar la máxima serenidad" (Horkheimer y Adorno, 2009, p. 142), siendo la máxima de su comportamiento obrar mal y no arrepentirse. Maiso comenta al respecto cómo se evidencia "el destino del placer divinizado en el proceso de desencantamiento del mundo, que es recuperado solo desde la gélida racionalidad del sujeto monadológico y asilado que se desentiende del sufrimiento ajeno y de compasión" (Maiso, 2010, pp. 246-247).

El desatender el sufrimiento de otros comienza con la "apatía”, como la entendió Kant. Por tanto, si la virtud ha de ser considerada, debe presuponer la "apatía”, que de manera similar al Marqués de Sade creía en la "apatía moral” como insensibilidad ante los estímulos de los sentidos. Se trata de menospreciar los sentidos, el entusiasmo y la espontaneidad en aras de centrar todo comportamiento en la racionalidad funcional que planifica hasta los últimos movimientos orientados hacia distintos fines.

Esa apatía señala el repliegue de la espontaneidad de los individuos a la esfera privada, que precisamente así se constituye como la forma de existencia genuinamente burguesa. El estoicismo - es decir, la filosofía burguesa - facilita a los privilegiados, ante el sufrimiento de los otros, mirar de frente a la amenaza que pesa sobre ellos. (Horkheimer y Adorno, 2009, p. 142)

El individuo burgués que goza de una posición privilegiada en la sociedad mantiene su estatus al ejercer formas de dominación sobre los demás individuos subordinados a quienes observa con actitudes apáticas e indiferentes. Pero también, esta caracterización del sujeto moderno se enriquece con esta mirada, que penetra en la intimidad del individuo y nos va dejando una imagen que disuena con la clásica definición de un hombre racional unitario orientado al conocimiento y al trabajo, dueño de su voluntad y de sus decisiones. Esa unidad — entre la razón, la buena voluntad y sus acciones asertivas - , la mantiene y la alcanza efectivamente gracias a la identidad, pero esa identidad con el señor burgués propietario de su empresa, capaz de manejar sus negocios y competir en los más variados escenarios en aras de la conservación, que lo hace un ser fuerte, debe negar su espontaneidad y relegarla al espacio privado. Pero el espacio privado también está sometido a contradicciones que el individuo aparentemente controla. Su sexualidad y sus relaciones afectivas también están influidas por una moral cristiana que se enfrenta a las reclamaciones de una aparente liberalidad 
de los sentidos que deben ser suyos, pero que no puede dejarlos sueltos, sino que debe dominar y doblegar a la razón.

Para Juliette, los sentimientos deben endurecerse y, si es el caso, traspasar los límites legales y morales para evitar estas confrontaciones entre la razón práctica y el placer o la satisfacción. Por esta razón, ella exhorta a los individuos a elaborar planes con sangre fría, que sean útiles para los fines individuales, como alcanzar el placer sin remordimientos, así este involucre algún crimen; con esto, el vicio es elevado al rango de virtud. Juliette encarna en la literatura la subjetividad burguesa. Ella ha tomado a la ciencia como credo rechazando toda veneración religiosa que no pueda ser probada: la fe en un dios, la superioridad del bien sobre el mal, la salvación del pecado. A cambio de estas creencias avala racionalmente la trasmutación de los valores, como cuando se pregunta: “¿Se necesitan pretextos para cometer un crimen?” (Sade, 1797, citado por Horkheimer y Adorno, 2009, p. 143), le pregunta la princesa Borguese a Juliette, acorde con el pensamiento de su amiga. Por tanto, para Juliette y su idea de individuo moderno, las decisiones prácticas no requieren más sustento que el objetivo que persiguen, y si este es el éxito, la ganancia o el placer, entonces no importa que en medio haya quedado un hombre muerto, pues simplemente ese hombre fue débil y no fue capaz de defender su vida. El señor Verneuil, otro personaje de la obra literaria estudiada, critica la defensa de Rousseau a la igualdad y la fraternidad: Verneuil tacha de tonto e insensato a Rousseau, pues las evidencias muestran que la naturaleza ha dotado a unos hombres de fuerza, belleza e inteligencia y a otros de lo contario. Por tanto,

¿Cómo quiere usted, en efecto — dice Verneuil- que quien ha recibido de la naturaleza la alta idoneidad para el delito, ya sea por la superioridad de su fuerza o por la finura de sus órganos, ya sea por su educación aristocrática o por su riqueza; ¿cómo quiere, digo, que ese individuo sea juzgado según la misma ley con la que se juzga a otro a quien todo induce a la virtud y a la moderación? ¿Sería quizá más justa una ley que castigue en igual medida a estos hombres? ¿Es natural que a aquel a quien todo induce a hacer el mal se lo trate como a aquel a quien todo impulsa a comportarse con moderación? (Sade, 1797, citado por Horkheimer y Adorno, 2009, p. 145)

El individuo surgido de esta época ilustrada es un ser superior, goza de dones naturales para alcanzar metas de riquezas y poder, que serían juzgadas como delito siguiendo un modelo racional basado en principios de la igualdad y la fraternidad. Verneuil critica 
sin tapujos esos principios virtuosos y compasivos, pues el individuo privilegiado orienta sus actos guiado por la astucia que le permite calcular sus ganancias, por los instrumentos racionales que faciliten adquirir la riqueza o el poder. El modelo de individuo moderno exitoso privilegia sus dones naturales y toma actitudes indiferentes y apáticas ante los demás individuos que carecen de estas características superiores, sobre quienes pueden recaer acciones negativas, es decir, decisiones delictivas que causan el mal ante los individuos inferiores, pero proveen la ganancia para los superiores.

El análisis literario nos muestra cómo Historia de Juliette refleja que la conformación de la subjetividad va acompañada de la formación moral, donde la identidad tiene múltiples sentidos; tanto la identidad subjetiva como la moral son producto de una tensión entre la dominación de los otros para alcanzar el éxito en el mercado y la dominación de los sentimientos propios, que superan principios como el bien o la igualdad en aras de la propia conveniencia. La crítica a la acepción de identidad que viene de la dominación de la naturaleza aparece luego de eliminar las tradiciones antiguas, así como de ensalzar una individualidad que reivindica la propia naturaleza, pero no porque ella haga parte del sí mismo, sino que ella justifica las capacidades para el dominio.

\section{Sufrimiento en la relación sujeto-objeto}

Al hacer parte de la constitución del sujeto, el sufrimiento también interviene en la relación del sujeto con los objetos. Como hemos visto, Adorno plantea que, según el pensamiento dialéctico, los objetos son más que su concepto, lo cual contradice la norma de la adecuación entre objeto y concepto. Si la dialéctica muestra que los objetos no se adecúan siempre al concepto, o que su adecuación no es completa, entonces la identidad pretendida entre uno y otro es falsa (Adorno, 1975, p. 19). El pensamiento que presenta esta adecuación entre objeto y concepto está marcado por la apariencia, por tanto, la verdad que expresa su concepto es la apariencia de la adecuación. Por ello, Adorno afirma que la verdad y la apariencia son inseparables. Esta estructura de adecuación entre objeto y concepto no puede cambiarse fácilmente, y solo cabría un recurso, que es el que propone el autor, de romper la pretensión de que la apariencia — el concepto - corresponda a la identidad total con el objeto. ¿Qué es lo problemático? Que los objetos son más diversos y no se acomodan a la identidad que pretende el concepto; los objetos cualitativamente distintos no encajan en el concepto, no se identifican con él, lo cual significaría que estos objetos serían negados por el conocimiento o que el sujeto cognoscente tendría que forzar el objeto para hacerlo 
caber en el concepto. Esta situación muestra que el concepto refleja una apariencia falsa o al menos incompleta. Adorno propone entonces que el sujeto reflexione acerca de las contradicciones que entraña el conocimiento de un objeto, reflexión que llevaría al sujeto a percatarse de las diferencias características que tiene el objeto y que no han sido tomadas en cuenta por el concepto, e incluso la irracionalidad que implica la obligación de someter la variedad de los objetos es sometida por el sujeto. O más bien, el sujeto se somete a la imposición de la identidad del concepto. José Antonio Zamora dice que la crítica adorniana al pensamiento identitario se basa en la falsa adecuación de lo universal en lo singular, y cuando en la esfera social el sistema social se impone sobre el sujeto, esta imposición implica un sufrimiento que padece el sujeto (Zamora, 2004, p. 209).

Según Adorno, "[l]a objeción de que sin sujeto cognoscente no habría conocimiento del objeto es insuficiente para demostrar la prioridad ontológica de la conciencia" (Adorno, 1975, p. 187). Adorno entiende que la actividad consciente del sujeto, además de ser racional, se deriva de la energía vital del hombre, es decir, de su energía libidinal, la cual, para él, hace parte del mismo ser humano. Entiendo entonces que con ello Adorno quiere decir que la conciencia humana no solo es racional, pues también responde a otros impulsos, quizás inconscientes, y por tanto, las teorías kantianas o husserlianas no tienen en cuenta el origen vital de la conciencia. Adorno concluye parcialmente que el objeto solo puede ser conocido por el sujeto en su compenetración con él y que la subjetividad también necesita el componente objetivo.

Adorno insiste en señalar que el sujeto no tiene una conciencia racional únicamente, sino que esta se deriva más bien de impulsos de la libido, y por tanto, el deseo y los impulsos corporales hacen parte del mismo sujeto, pues la conciencia hace parte del sujeto vivo y por tanto hace parte de su cuerpo. "Sin ninguna relación con la conciencia empírica, la del yo vivo, no habría conciencia trascendental, puramente espiritual" (Adorno, 1975, p. 187). Así, el objeto solo puede ser conocido en la compenetración ${ }^{5}$ de este con el sujeto, en el sentido de que este sujeto se vierte sobre el objeto con su conciencia racional y también con su conciencia viva, libidinal, para abrir su conciencia tanto al objeto establecido por el concepto, como a los objetos diferentes a los cuales accederá con el deseo y los impulsos. Si prevalece la preeminencia del objeto,

5 Compenetración significa una mezcla entre el sujeto completo y la materialidad del objeto, sin seguir un determinado método, sino dejando que las distintas maneras de ser del sujeto puedan penetrar en la otra materialidad. 
el sujeto se referirá a este siempre bajo determinaciones objetivas, pero no reflexionará subjetivamente sobre las condiciones y determinaciones tanto del objeto como del sujeto. Pero estos dos componentes no se identifican entre sí, sino que se oponen, lo que da lugar a la negatividad, que pretende disolver la identidad. Con el espíritu la verdad y la apariencia surgen simultáneamente: hay verdad porque nada escapa a la dominación que redujo al objeto a su forma; y hay mentira en la apariencia - en el concepto-, porque esta reducción a la pura forma transmuta al objeto en otra cosa, en lo que el sujeto creía que debería ser. Por tanto, cuando surge una relación dialéctica, para el sujeto que se sabe racional y pulsional, los objetos aparecen de manera diversa, aquellos que se adecúan al concepto como aquellos contradictorios y diferentes del concepto; entonces la apariencia se contrasta con una verdad que también se debe a la dominación.

Adorno continúa examinando la relación del sujeto con los objetos hasta llegar al materialismo, como el momento de la Modernidad en que el objeto se vuelve totalmente material, sin pretender defender que la actividad espiritual sea equiparable con actividades cerebrales (Adorno, 1975, p. 195). Entiendo que lo que quiere decir es que la crítica idealista del materialismo no debe contentarse con afirmar una doctrina de los datos inmediatos, y por ello, ese materialismo científico, que equipara al espíritu con las percepciones y las actividades cerebrales, reduce los procesos de la conciencia a los ideales de la ciencia, y así, se confirmaría la validez de las afirmaciones científicas.

La manera de controlar la verdad de los juicios científicos ha consistido en seguir los pasos establecidos, es decir, el método, para llegar a ellos; por ejemplo, descubrir los errores o faltas en que incurrió un sujeto cognoscente para llegar a un juicio falso o a una contradicción. Pero, en este caso, cuando el sujeto busca los errores de su juicio enfatiza en el medio, en el proceso, pero no en el contenido o en los actos subjetivos. Kant ya había señalado que cuando se le muestran a un sujeto las faltas que ha cometido en la aplicación de las reglas matemáticas, el error se ubica en la aplicación del método, pero para Kant, no es que el cálculo matemático necesite actos subjetivos como componente de la objetividad del resultado. De esta manera, recobra vigencia la alusión a la segunda naturaleza planteada en el primer apartado (1.2). En dicha mención se intentaba comprender cómo la historia natural se entrecruza con la filosofía de la historia, y cómo aparece en medio la segunda naturaleza como el producto de la enajenación del mundo de las mercancías, siendo este la realidad de cosas sin sentido donde debemos sobrevivir. 
En el presente apartado, la segunda naturaleza surge cuando el sujeto lleva a cabo el proceso de conocimiento ligado al mismo proceso de la producción; si la producción de mercancías moderna, basada en la técnica, ha llevado a la enajenación del hombre, el proceso de conocimiento que divide los procesos subjetivos de la conciencia de los métodos para conocer al producir ambigüedades y contradicciones no resueltas ni encaradas, entonces este proceso privilegia los resultados del conocimiento, los datos y la validación de estos, lo que hace de ellos también una segunda naturaleza. Adorno explica las consecuencias de esto de la siguiente manera:

El imperio del control de validez y aspiraciones clasificatorias hacen que los datos de la conciencia sean distinguidos a continuación de sus sutiles transiciones, sobre todo de las que enlazan con las activaciones espirituales del cuerpo, que contradicen la pretendida solidez de aquellos. (Adorno, 1975, p. 197)

En el campo del conocimiento, Adorno señala que la segunda naturaleza tiene particularidades, como la separación entre cuerpo y espíritu, que enfatiza en el espíritu y en sus métodos para asegurar de esta manera la preeminencia del método y desdeñar las posibilidades que pueda conocer las contradicciones y criticar las ambigüedades. Este conocimiento sería entonces también una forma de enajenación. Por tanto, es importante resaltar que, para Adorno, esta nueva metafísica del método no solo evade las ambigüedades y contradicciones que se presentan en la relación sujeto/objeto en el proceso de conocimiento, sino que contribuye a evadir los impulsos corporales que influyen en la conciencia, en la construcción de los datos de la conciencia, y altera la pureza pretendida de estos. Esta ruptura o alteración de las relaciones o enlaces entre "las actividades espirituales del cuerpo" y los datos de la conciencia se presentan también en otros ámbitos, como en la comprensión de la voluntad y de la libertad. Según Adorno:

Cuando en La metafísica de las costumbres Kant construyó la libertad como libertad con respecto a la sensación, rindió sin querer homenaje a lo mismo que quería eliminar. La separación absoluta entre cuerpo y espíritu, la cual en el fondo va a parar al predominio de este, es tan imposible de salvar como la jerarquía idealista de los datos. Ambos han venido a parar históricamente en oposición en el transcurso del desarrollo de la racionalidad y el principio yo. Sin embargo, ambos se necesitan mutuamente. (Adorno, 1975, p. 197) 
De esta cita puedo resaltar que Adorno encuentra en un primer momento de análisis crítico del proceso de conocimiento, una fisura que da como origen una ambigüedad entre los datos de conocimiento y el desconocimiento de los impulsos de la conciencia, así como de los movimientos espirituales del cuerpo. Este desconocimiento dará lugar al sufrimiento en este proceso cognoscitivo, y también a un sufrimiento en la ruptura entre la libertad y la voluntad, con los impulsos corporales.

Los idealistas encontraron que, para pasar del espíritu a la concreción individual se requería de una actividad, así que el camino fue tomar el medio del trabajo, utilizando a los individuos como meros medios, lo que degradó su condición a trabajadores que sirven al señor. Al respecto, Adorno afirma: "El concepto idealista de espíritu vive de explotar la transición al trabajo social, es decir: prescinde de los actores particulares, absorbidos en la actividad universal, y transfigura sin dificultad a esta, convirtiéndola en realidad objetiva" (Adorno, 1975, p. 200). Por tanto, la crítica de Marx a esta propuesta del idealismo cobra una gran importancia, pues él logró hacer compatibles esos individuos que trabajan, en lo real y lo individual, con la teoría y convertir la ley del valor en una teoría del capitalismo que pasa por encima de las personas. No se trata en la mediación dialéctica de lo universal y lo particular de que ahora prime lo particular, pues entonces la teoría no podría explicar ninguno de los dos componentes. Una interpretación posible es que Adorno quiere resaltar que el espíritu no puede ser sin la particularidad concreta y material, pero tampoco esa realidad material puede existir sin espíritu. Por ello dice que no es posible siquiera imaginar al sujeto trascendental sin sociedad, aunque el idealismo intente desterrar al materialismo. "El materialismo es denigrado primero como inferior — no sin la ayuda de su innegable falta de reflexión filosófica-, para ser luego brillantemente refutado" (Adorno, 1975, p. 201). Por tanto, aunque los dos polos son importantes y necesarios, Adorno enfatiza en la concreción material, pues esta ha sido rechazada y escondida por el idealismo. La transición entre el espíritu y su otro, que para la mayoría de los idealistas es devenir, se encuentra con varios obstáculos. Primero, la actividad del paso del espíritu a lo otro es entendida como un paso del Absoluto a la inmanencia, una actividad del espíritu que se humaniza pero que no puede atribuirse a nadie ni a nada, únicamente a lo viviente.

Esto hace que la naturaleza se infiltre como un componente en el concepto que más se eleva por encima de todo naturalismo, el de la subjetividad como unidad sintética de la apercepción. Solo en cuanto el yo es de por sí no-yo se 
relaciona con este, "hace" algo, incluso cuando lo que hace es pensar. (Adorno, 1975, p. 202)

Con lo anterior, puedo decir que Adorno afirma que el sujeto no es solo espíritu, sino espíritu y naturaleza, el no-yo del sujeto es la naturaleza que se expresa en la acción o en el movimiento, pero también cuando no hace nada, como cuando piensa. Adorno quiere vincular al espíritu con la naturaleza en una relación donde no prime ninguno de ellos. Ante la controversia entre cuerpo y espíritu planteada por Schelling (1964, citado en Adorno, 1975, p. 202), según la cual el espíritu tiene prioridad sobre el cuerpo, Adorno advierte que el espíritu está tan implicado en la existencia que es irreductible a ella, por tanto, sería imposible desglosarlos cada uno por separado.

Ambos, cuerpo y espíritu, son abstracciones de la experiencia. Su radical diferencia es algo puesto, reflexión sobre una "autoconciencia" del espíritu adquirida históricamente y distanciada de aquello que niega para poder afirmar su identidad. Todo lo espiritual es modificación de un impulso corpóreo; esta representa la conversión cualitativa en lo que es más que ser. Impulso es, como dijo Schelling, la forma precursora del espíritu. (Adorno, 1975, pp. 202-203)

En esta cita se patentiza la propuesta adorniana de la relación entre cuerpo y espíritu, la cual no se caracteriza por una funcionalidad o instrumentalización de la relación, sino que los dos se compenetran de tal manera que son irreductibles el uno al otro en la experiencia, siendo esa experiencia una reflexión sobre ella misma. Esta experiencia reflexionada implica aceptar lo negado, que generalmente es el cuerpo, para poder "afirmar su identidad", y así el impulso corporal cobra un lugar en el yo, en la formación de la subjetividad. Y por ello, Adorno expone un apartado que ha sido muy comentado en la literatura sobre su filosofía, aquel que pretende comprender la negatividad. Dice el filósofo:

Los datos al parecer fundamentales de la conciencia son otra cosa de lo que se cree. En la dimensión de gusto y disgusto se infiltra lo corpóreo. Todo dolor y toda negatividad, motor del pensamiento dialéctico, son la figura de lo físico a través de una serie de mediaciones que pueden llegar hasta hacerle irreconocible. (Adorno, 1975, p. 203) 
Esta cita es muy importante en este contexto epistemológico, pues no solo nos muestra cómo se cuela la corporalidad en los datos de la conciencia, sino que el dolor y la negatividad son los impulsos del pensamiento dialéctico. Conocedores de Adorno como Zamora (2004, pp. 209 y ss.), Zöller (2004, p. 202) y Kohlmann (1997, p. 140) se apoyan en esta cita para afirmar que el centro del pensamiento adorniano es el sufrimiento, que viene de una afectación corporal que ocurre cuando el sujeto piensa y reflexiona. Siguiendo estas pistas pretendo comprender en qué consiste el sufrimiento para Adorno, pues no solo se trata de un sentimiento provocado por un dolor momentáneo o una afectación producida por un accidente o una agresión. Para Adorno, el dolor y el sufrimiento hacen parte de la cotidianidad, de nuestra propia existencia, en la cual nuestro cuerpo recibe los datos externos y también internos, y en lugar de comprenderlos en su dimensión y significado las mediaciones culturales los transforman en otra cosa, negándolos. En la diversidad el sujeto asume una postura moral, al surgir un impulso por conocer más ampliamente el contexto y la amplitud de facetas que los objetos y las personas le ofrecen, impulsos que lo conducen a reflexionar sobre sus decisiones.

Al negar la existencia del cuerpo como la mediación principal de los datos de la conciencia, los datos mismos se transforman en mediaciones idealizadas. Esas mediaciones, como los prejuicios, las normas o las costumbres, matizan estos datos hasta convertirlos en algo "irreconocible" para el sujeto; pero estos datos corporales se "infiltran", dice el autor, por tanto, pareciera que no tuvieran permiso para acceder a la conciencia, juzga que la subjetividad cognoscente estuviera montada sobre una conciencia separada de su propia corporalidad. Para Adorno, el pensamiento dialéctico no es posible sin esta negatividad del cuerpo que es capaz de sentir el dolor y el sufrimiento que este produce. Por ello, pensar dialécticamente implica dejar hablar a los impulsos tanto corporales como espirituales: "La dimensión corporal, de suyo contradice al espíritu en el espíritu, queda amortiguada en los datos sensoriales de la subjetividad en algo así como una huella gnoseológica” (Adorno, 1975, p. 203).

Adorno profundiza en la importancia de las sensaciones corporales para la conciencia, pues el componente corporal "sobrevive en el conocimiento como su inquietud que le pone en marcha y se reproduce insatisfecha en su proceso" (Adorno, 1975, p. 203). Estas sensaciones corporales aparecen en el proceso de conocimiento y generan inestabilidad, por tanto, impulsan preguntas, formulaciones críticas o creativas. Adorno afirma que ese desequilibrio convierte la conciencia tranquila en desgraciada, 
pues ofusca al espíritu cuando es separada del cuerpo. Si esto ocurre, si la conciencia se separa de sus sensaciones corporales no necesitará del impulso del espíritu: "La conciencia desgraciada le recuerda negativamente su componente somática" (Adorno, 1975, p. 203).

Para Adorno el componente somático es tan importante que, para él, el espíritu puede tener alguna esperanza para seguir adelante y oponerse a la filosofía de la identidad, es decir, a esa filosofía que él quiere criticar, si se percata de su propio cuerpo. Si el espíritu no puede percatarse de su propio cuerpo capaz de percibir el sufrimiento propio y el ajeno, el "sufrimiento absurdo en el mundo", entonces la dominación continúa, la identidad permanece y el mito se reproduce. El pensamiento identitario quiere negar el dolor en el mundo. Según Adorno:

La más mínima huella de sufrimiento absurdo en el mundo en que vivimos desmiente toda la filosofía de la identidad. Lo que esta intenta es disuadir a la experiencia de que existe el dolor. "Mientras haya un solo mendigo, seguirá existiendo el mito": la filosofía de la identidad es mitología en forma de pensamiento. El componente somático recuerda al conocimiento que el dolor no debe ser, que debe cambiar. "Padecer es algo perecedero". (Adorno, 1975, p. 204)

La última sentencia expresa que el dolor causa o efectúa en quien lo padece un sufrimiento que llega a afectar su ser y su vida, pero a la vez, el dolor perece, se convierte en impulso, como acicate. Surge la pregunta de ¿qué entiende Adorno por perecer?, ¿qué es aquello que perece? Interpreto que si el sujeto padece al conocer y relacionarse en un mundo injusto que produce dolor, tiene que pasar a otro momento y sustituir el dolor, dejarlo perecer. El sujeto tendría que hacerse consciente y tomar una postura crítica de la sociedad que produce el dolor, y reaccionar ante el sufrimiento ${ }^{6}$. Por ello tendría que pasar a la praxis.

La última afirmación de la cita enfatiza que la corporalidad es negatividad, "es el punto en que convergen lo específicamente materialista y lo crítico, la praxis que cambia la sociedad" (Adorno, 1975, p. 204). Adorno apunta a formular una praxis que debería ser emancipadora, pero que se enfrenta con los sistemas actuales que buscan la

6 Kohlmann analiza este párrafo con sumo cuidado, pues considera que la afirmación "padecer es perecer" contradice la conciencia humana, que llevada a la praxis, hace de la vida un absurdo (Kohlmann, 1997, p. 140). 
sobrevivencia de la humanidad que, de manera contradictoria, van dirigidos contra el sufrimiento, es decir, lo niegan al afirmar que la vida social actual busca el bienestar. El sistema de producción capitalista busca la felicidad de la mayoría, eliminar el sufrimiento y el dolor, y este es su telos, el cual conduciría a la solidaridad para con todos. Pero, de manera contradictoria, el materialismo actual no ha emancipado al mundo: "En vez de comprender y transformar la conciencia la sigue esclavizando" (Adorno, 1975, p. 205).

Adorno vuelve a las reflexiones que formuló en "El concepto de ilustración”, incluido en Dialéctica de la Ilustración, acerca de la segunda naturaleza, como aquella producción humana que nos ha alejado de la naturaleza para sobrevivir como humanos; pero esa segunda naturaleza ha roto lo más natural que tenemos, nuestra corporalidad, y con ella la capacidad de sentir alegría y dolor, de producir dolor o evitarlo, porque nuestra conciencia no permite que el impulso le diga qué hacer, qué pensar, qué reflexionar, cómo asumir una praxis que le permita evitar el dolor y cambiar en algo la sociedad. Pero, aun así, según Adorno, las acciones que la humanidad lleva a cabo están dirigidas a la autoconservación que evita el sufrimiento físico, y al mismo tiempo, evita la reflexión y la crítica. Pues evitar el sufrimiento negando la corporalidad es lo mismo que reproducir un nuevo sufrimiento que no sabemos que existe. El sufrimiento hace parte central de la subjetividad y, por tanto, del conocimiento, sin embargo, la sociedad se configura de tal manera que tiende a eliminarlo e ignorarlo, lo que lleva la contradicción a una situación difícil de resolver.

Hasta aquí he intentado responder en qué consiste el sufrimiento, concepto que Adorno sitúa en el corazón del sujeto moderno. En primer lugar, en la sociedad actual el sujeto ha tenido que reprimir sus sentimientos al endurecer su carácter y sus impulsos producto de una cultura de la dominación, y, como esta represión hace parte de un largo proceso de socialización y mediación cultural, el individuo ha ido endureciendo su capacidad de sufrir con otros su dolor, reprimiendo la historia arcaica y relegando los mitos al olvido. En segundo lugar, en la relación sujeto/objeto, es decir, en la interacción del sujeto con el mundo, la primacía se le ha otorgado al método, pues el proceso de conocimiento está ligado al de producción de mercancías donde prima la técnica. Adorno se separa de esta manera de relación del sujeto con el objeto, pues para él la conciencia también goza de impulsos, es decir, el cuerpo también media en la relación con el mundo. Si no hay un reconocimiento de los impulsos corporales en el proceso de conocimiento, también se produce sufrimiento. Pero debo añadir que 
según la interpretación de Zamora (2010, p. 210), el sufrimiento está mediado por la reflexión del sujeto, sin la cual no sería posible que este pudiera notar la falsedad del sistema económico y social en que vive; además, el mismo sistema no tendría ningún poder de dominar a través de los distintos medios con los que cuenta, como el proceso de socialización, los medios de comunicación de masas, las ideologías políticas, entre otros.

\section{Referencias}

Adorno, Th. W. (1975). Dialéctica negativa. Madrid: Taurus.

Adorno, Th. W. (2010a). Escritos filosóficos tempranos. Madrid: Akal.

Adorno, Th. W. (2010b). La idea de historia natural. En Escritos filosóficos tempranos (pp. 315-333). Madrid: Akal.

Benjamin, W. (2010). Origen del drama barroco alemán. En R. Tiedemann y H. Schweppenhäusser (eds.), Obras, libro I. vol.1 (pp. 375-408). Madrid: Abada.

Buck-Morss, S. (1981). Origen de la dialéctica negativa. Theodor W. Adorno, Walter Benjamin y el Instituto de Frankfurt. Ciudad de México: Siglo XXI.

Horkheimer, M. y Adorno, Th. W. (2009). Dialéctica de la Ilustración. Madrid: Trotta.

Kohlmann, U. (1997). Dialektik der moral Untersuchungen zur Moralphilophie Adornos. Lüneburg: Kassel Universität.

Maiso, J. (2010). Elementos para la reapropiación de la teoría crítica de Theodor Adorno. Salamanca: Universidad de Salamanca.

Zamora, J. A. (2004). Theodor W. Adorno. Pensar contra la barbarie. Madrid: Trotta.

Zöller, Th. (2004). Leiden als Vermittlungskategorie von Subjekt/Objekt. En J. Becker y H. Brakemeier (eds.), Vereinigung freier Individuen. Kritik der Tauschengesellschaft bei Theodor Adorno (pp. 200-216). Hamburg: VSA-Verlag.

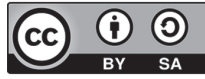

